\title{
Eficiência agronômica e qualidade sanitária de biofertilizantes aplicados no solo em cultivo orgânico da alface
}

\section{Agronomic efficiency and sanitary quality of biofertilizers applied to the soil in organic lettuce cultivation}

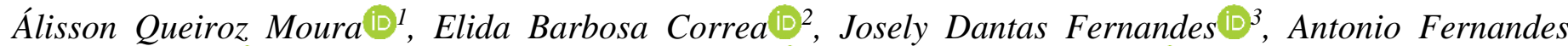 \\ Monteiro Filho ${ }^{(14}{ }^{4}$, Tricya Neroyldes Farias Ferreira ${ }^{(15}{ }^{5}$, Alexandre Costa Leão ${ }^{(D 6}$
}

\begin{abstract}
${ }^{1}$ Agroecólogo, Universidade Estadual da Paraíba, Lagoa Seca, +5583993753448, alissonq8@ @gmail.com. ${ }^{2}$ Doutora em Proteção de Plantas, Professora, Universidade Estadual da Paraíba, Lagoa Seca, elida.uepb@gmail.com. ${ }^{3}$ Doutor em Recursos Naturais, Técnico em Agropecuária, Universidade Estadual da Paraíba, Lagoa Seca, joselysolo@yahoo.com.bre. ${ }^{4}$ Doutor em Engenharia Agrícola, Técnico em Agropecuária, Universidade Estadual da Paraíba, Lagoa Seca, afernandesmf@gmail.com. ${ }^{5}$ Especialisa em Análise Clínica, Técnica de Laboratório, Universidade Estadual da Paraíba, Lagoa Seca, tricyafarias@gmail.com. ${ }^{6}$ Mestre em Manejo de Solo e Água, Professor, Universidade Estadual da Paraíba, Lagoa Seca, acostaleao@yahoo.com.br.
\end{abstract}

\section{A R T I G O}

Recebido: $14 / 05 / 2020$

Aprovado: 03/09/2020

Palavras-chave:

Lactuca sativa $\mathrm{L}$.

Adubação orgânica

Produção agroecológica

SOLVER

Key words:

Lactuca sativa $\mathrm{L}$.

Organic fertilization

Agrocological production

SOLVER.

\section{R E S U M O}

A adubação de hortaliças por meio de biofertilizantes é utilizada principalmente pela agricultura orgânica. No entanto, são escassos os trabalhos publicados avaliando a microbiota potencialmente patogênica a humanos nos biofertilizantes, assim como sua formulação conforme as necessidades nutricionais da cultura. Desse modo, o objetivo com este estudo foi formular dois biofertilizantes otimizados, avaliar suas características sanitárias (microbiológicas e parasitológicas) e eficiência agronômica no cultivo orgânico da alface crespa. O experimento foi conduzido em condições de campo em Lagoa Seca, Paraíba. O arranjo experimental foi em blocos casualizados, em esquema fatorial $(2 \times 6)$, com 3 repetições, sendo dois biofertilizantes otimizados (BIO I e BIO II) e seis concentrações $(0,20,40,60,80$ e $100 \mathrm{~mL})$. A alface crespa foi adubada com os dois biofertilizantes, formulados com materiais orgânicos, e submetidos à fermentação aeróbica por 96 dias. O BIO II não teve contaminação com micro-organismos patogênicos ao homem, enquanto o BIO I apresentou contaminação com coliformes totais e fecais, Ascaris lumbricoides, Ancilostomideo spp., Entamoeba histolystica e Entamoeba coli. A aplicação do BIO I e BIO II promoveu aumento no rendimento da produção total, produção comercial, número de folhas, massa seca do caule e raiz. No entanto, a massa seca das folhas não diferiu do tratamento controle, independente do biofertilizante. Maiores estudos devem ser realizados para investigar o efeito residual dos biofertilizantes e, outros métodos de aplicação como pulverização foliar para o BIO II.

\section{A B S T R A C T}

The fertilization of vegetables by means of biofertilizers is mainly used by organic agriculture. However, there are few studies published evaluating the potentially pathogenic microbiota to humans in biofertilizers as well as its formulation according to the nutritional needs of the crop. Thus, the objective of this study was to formulate two optimized biofertilizers and evaluate their sanitary characteristics (microbiological and parasitological) and agronomic efficiency in the organic cultivation of curly lettuce. The experiment was conducted under field conditions in Lagoa Seca, Paraíba. The experimental arrangement was in randomized blocks, in a factorial scheme $(2 \times 6)$, with 3 replications, being two optimized biofertilizers (BIO I and BIO II) and six concentrations $(0,20,40,60,80$ and $100 \mathrm{~mL})$. The curly lettuce was fertilized with two biofertilizers, formulated with organic materials, and submitted to aerobic fermentation for 96 days. BIO II did not have contamination with microorganisms pathogenic to humans, while BIO I presented contamination with total and fecal coliforms, Ascaris lumbricoides, Ancilostomideo spp., Entamoeba histolystica and Entamoeba coli. The application of BIO I and BIO II promoted an increase in total production yield, commercial production, number of leaves, dry mass of the

\footnotetext{
Revista Verde

ISSN 1981-8203

Pombal, Paraíba, Brasil
}

v. 15, n.4, out.-dez., p.346-352, 2020 doi: $10.18378 /$ rvads.v15i4.7958 
stem and root. However, the dry mass of leaves did not differ from the control treatment, regardless of biofertilizer. Further studies should be conducted to investigate the residual effect of biofertilizers and other application methods such as foliar spraying for BIO II.

\section{INTRODUÇÃO}

A alface (Lactuca sativa L.) é uma hortaliça folhosa rica em nutrientes importantes para a saúde humana, sendo a mais consumida no Brasil (ZIECH et al., 2014). Seu ciclo de cultivo é curto, o que demanda intenso processo de fertilização com fontes prontamente assimiláveis de fertilizantes minerais e sintéticos (PINHEIRO et al., 2019). Neste sentido, os efeitos nocivos da aplicação demasiada de fertilizantes minerais e sintéticos para o meio ambiente e saúde humana, tem sido amplamente discutido nas últimas décadas (LAPÔRTO et al., 2012; PINHEIRO et al., 2019; PERAZZOLI et al., 2020). Desse modo, a adubação orgânica utilizando biofertilizantes surge como alternativa para atender as necessidades nutricionais das plantas (PERAZZOLI et al., 2020).

O biofertilizante é um adubo líquido oriundo de digestão aeróbica ou anaeróbica, a partir da mistura de resíduos orgânicos, sendo acrescidos ou não de fontes minerais diluídas em água (FERNANDES et al., 2011; BISERRA et al., 2020). Resíduos orgânicos quando descartados incorretamente promovem sérios riscos ao meio ambiente, e por consequência, a saúde humana (DUARTE et al., 2012; BATISTA et al., 2019).

A utilização do biofertilizante ativa a microbiota do solo, melhora a estrutura física do solo, aeração, retenção de água e aumenta a fertilidade do solo, além disso, tem sido avaliado como defensivo fitossanitário no controle de doenças de plantas (SOUSA et al, 2012; MUELLER et al., 2013; ZIECH et al., 2014; SANTOS et al., 2019). No entanto, uma das principais dificuldades para a obtenção de biofertilizante otimizado para cada cultura, corresponde ao cálculo para balancear cada nutriente a partir de diferentes materiais orgânicos e da disponibilidade destes materiais no agroecossistema. Dessa forma, Fernandes et al. (2011) propõem o uso da ferramenta SOLVER para maximizar os produtos encontrados no agroecossistema e formular biofertilizante com sua composição química pré-definida.

Diversos autores têm publicado resultados satisfatórios no rendimento da alface cultivada com biofertilizantes, tanto no solo, como em sistema hidropônico (PINHEIRO et al., 2019; MONTEIRO FILHO et al., 2017), porém a utilização deste material sem a caracterização sanitária pode comprometer o seu uso e causar riscos à saúde humana (SILVA et al., 2012). Ante o exposto, o objetivo com este estudo foi formular dois biofertilizantes otimizados e avaliar sua eficiência agronômica e características sanitárias (microbiológicas e parasitológicas) no cultivo orgânico da alface crespa.

\section{MATERIAL E MÉTODOS}

O experimento foi conduzido durante o período de abril a junho de 2016, em campo no Centro de Ciências Agrárias e Ambientais (CCAA) da Universidade Estadual da Paraíba (UEPB), Lagoa Seca - PB ( $7^{\circ} 9$ 'S, $35^{\circ} 52^{\prime}$ ' W e altitude de 634 m). De acordo com a classificação de Köppen o clima da região é AS com temperatura mínima de $19{ }^{\circ} \mathrm{C}$ e máxima de $28^{\circ} \mathrm{C}$, com chuvas concentradas entre abril e agosto e precipitação pluvial anual acima de $700 \mathrm{~mm}$ (SANTOS et al., 2019). As especificações químicas do solo utilizado no ensaio encontramse na Tabela 1.

Tabela 1. Análise química do solo utilizado no experimento $(0-20 \mathrm{~cm})$

\begin{tabular}{cccccccccc}
\hline $\mathrm{pH}$ & $\mathrm{Ca}^{+2}$ & $\mathrm{Mg}^{+2}$ & $\mathrm{Na}^{+}$ & $\mathrm{K}^{+}$ & $\mathrm{H}+\mathrm{Al}$ & $\mathrm{SB}$ & $\mathrm{V} \%$ & $\mathrm{P}$ & $\mathrm{MO}$ \\
\hline $1: 2,5$ & & \multicolumn{7}{c}{$\mathrm{cmol}_{\mathrm{c} d m}{ }^{-3}$} \\
\hline 6,73 & 4,55 & 1,10 & 0,63 & 159 & 0,68 & 0,81 & 9,62 & 243 & 16,24 \\
\hline
\end{tabular}

SB: Soma de base. V\%: Saturação por bases. MO: Matéria Orgânica.

Foram formulados dois biofertilizantes otimizados com auxílio da ferramenta SOLVER do Microsoft Office Excel (FERNANDES et al., 2011) para atender as necessidades nutricionais da alface utilizando a recomendação quanto aos níveis da extração de nitrogênio, fósforo e potássio (41,4-5,654,3) proposta por Faquin e Andrade (2004). Os ingredientes utilizados (Tabela 2) foram homogeneizados uma vez a cada sete dias em reservatórios com capacidade de 200 L e fermentados de forma aeróbica. Os biofertilizantes se diferenciam em sua composição pela quantidade dos ingredientes e pela presença da manipueira apenas no BIO II (Tabela 2). A composição química dos ingredientes utilizados foi baseada nos níveis médios dos produtos.

$\mathrm{O}$ delineamento experimental adotado foi em blocos casualisados com o arranjo fatorial $(2 \times 6)$, sendo dois biofertilizantes (BIO I e BIO II) e 6 concentrações $(0,20,40$, 60,80 e $100 \mathrm{~mL}$ ), com três repetições, totalizando 36 unidades experimentais. Os blocos foram dimensionados com $12 \mathrm{~m}$ de comprimento e $1 \mathrm{~m}$ de largura. Cada bloco foi constituído por 12 unidades experimentais com espaçamento de $0,25 \mathrm{~m}$ entre plantas e filas, a qual as duas filas de plantas centrais correspondiam à área útil (4 plantas). A irrigação foi realizada por gotejamento quando necessário.

Os tratamentos foram estabelecidos de acordo com o biofertilizante e suas concentrações, sendo a testemunha estabelecida com aplicação apenas de água. Os tratamentos foram aplicados de forma manual no colo da planta, sempre após a irrigação e com intervalo de cinco dias após o transplante das mudas até atingir o padrão comercial, totalizando nove aplicações.

Após 96 dias de fermentação foram coletadas amostras dos biofertilizantes para avaliação das características sanitárias (microbiológicas e parasitológicas). As amostras foram encaminhadas para análise no Laboratório de Microbiologia do 
CCAA da UEPB, Lagoa Seca - PB. Posteriormente foram submetidas ao método oficial da Association of Official Analytical Chemistis (AOAC, 1995), para coliformes totais 35
${ }^{\circ} \mathrm{C}$, termotolerantes $45^{\circ} \mathrm{C}$ e Escherichia coli, respectivamente, utilizando a técnica de tubos múltiplos com diluição seriada a $10^{-8}$.

Tabela 2. Composição química e quantitativa dos ingredientes utilizados no preparo dos biofertilizantes (BIO I e BIO II). Composição química dos ingredientes

\begin{tabular}{|c|c|c|c|c|c|c|}
\hline \multirow[b]{2}{*}{ Nutrientes } & $\begin{array}{c}\text { Sangue de } \\
\text { aves }\end{array}$ & Vinhaça & C.B & C.M & Manipueira & Água \\
\hline & \multicolumn{6}{|c|}{-------------------------------------------------\%"-------------------------------------------------------- } \\
\hline $\mathrm{N}$ & 2,55 & 0,012 & 0,190 & 0,000 & 0,043 & 0,001 \\
\hline $\mathrm{P}$ & 0,05 & 0,005 & 0,190 & 3,700 & 0,026 & 0,000 \\
\hline \multirow[t]{2}{*}{$\mathrm{K}$} & 0,19 & 0,040 & 0,020 & 7,001 & 0,180 & 0,022 \\
\hline & \multicolumn{6}{|c|}{ Ingredientes utilizados no preparo de $200 \mathrm{~L}$ dos biofertilizantes $(\mathrm{Kg})$} \\
\hline $\mathrm{BIO} \mathrm{I}$ & 1,012 & 125,00 & 1,000 & 0,010 & 0,000 & 72,978 \\
\hline BIO II & 0,673 & 50,000 & 2,500 & 0,100 & 7,208 & 139,519 \\
\hline
\end{tabular}

C.B: coração de bananeira. C.M: cinza de madeira. BIO I: Biofertilizante I. BIO II: Biofertilizante II.

Para as análises parasitológicas utilizou-se a técnica de sedimentação (TAKAYANAGUI et al., 2001). Para tanto, 100 $\mathrm{mL}$ de cada biofertilizante e $250 \mathrm{~mL}$ de água destilada e autoclavada foram homogeneizadas manualmente durante 30 segundos. Posteriormente, esta suspensão foi filtrada com gaze esterilizada em recipientes previamente esterilizados, permanecendo em repouso por 24 horas em temperatura ambiente. Após este período o sobrenadante foi desprezado e o sedimento analisado em triplicata, por meio de exame em microscópio ótico, utilizando as objetivas de 10 e 40 X para ovos ou larvas de helmintos.

As mudas de alface crespa (Elba Topseed®) foram produzidas em bandejas de polietileno, utilizando três partes de solo e uma de esterco como substrato. O transplante ocorreu quando as mudas apresentaram entre quatro a cinco folhas.

A colheita foi realizada aos 45 dias após o transplante. Em seguida foram avaliados os seguintes parâmetros: produção total (PT); produção comercial (PC); número de folhas (NF); massa seca das folhas (MSF); massa seca do caule (MSC) e massa seca da raiz (MSR). As massas secas foram obtidas após secagem a $50{ }^{\circ} \mathrm{C}$ em estufa de circulação de ar até atingir peso constante.
As variáveis analisadas foram submetidas ao teste de normalidade de Shapiro e Wilk, e homogeneidade de variâncias de Bartlett. Posteriormente, foram submetidas à análise de variância (ANOVA) pelo teste $\mathrm{F}$ e no caso de significância, realizou-se análise de regressão polinomial para desdobramento dos efeitos das concentrações dos biofertilizantes. $\mathrm{O}$ teste de Tukey $(\mathrm{p} \leq 0,05)$ foi utilizado para comparar as médias dos tipos de biofertilizantes. Para estas análises utilizou-se o software estatístico SISVAR (FERREIRA, 2011).

\section{RESULTADOS E DISCUSSÃO}

Após 96 dias da preparação, o BIO I apresentou contaminação com coliformes e parasitas relacionados à saúde humana como Ascaris lumbricoides, Ancilostomideo spp., Entamoeba histolystica e Entamoeba coli (Tabela 3 e 4).

Observa-se que o BIO II não apresentou contaminação (Tabela 3 e 4) mesmo utilizando em sua formulação a mesma água do BIO I. Este resultado pode estar relacionado à formulação (ingredientes) dos biofertilizantes, uma vez que apenas o BIO II teve manipueira em sua formulação (Tabela 2).

Tabela 3. Número mais provável (NMP $100 \mathrm{~mL}^{-1}$ ) de coliformes totais, coliformes termotolerantes e presença de Escherichia coli e Salmonela spp., após 96 dias de digestão aeróbica dos biofertilizantes (BIO I e BIO II).

\begin{tabular}{|c|c|c|c|c|c|c|c|c|}
\hline & \multicolumn{2}{|c|}{$\begin{array}{l}\text { Coliformes totais }{ }^{-1} \\
\left(35^{\circ} \mathrm{C}\right)\end{array}$} & \multicolumn{2}{|c|}{$\begin{array}{c}\text { Coliformes termotolerante }{ }^{-1} \\
\left(45^{\circ} \mathrm{C}\right)\end{array}$} & \multicolumn{2}{|c|}{$\begin{array}{l}\text { Intervalo de confiança } \\
(95 \%)\end{array}$} & \multirow[t]{2}{*}{$\begin{array}{l}\text { Escherichia } \\
\text { coli }\end{array}$} & \multirow[t]{2}{*}{ Salmonela spp. } \\
\hline & CT & $\begin{array}{c}\text { NMP } \\
100 \mathrm{~mL}^{-1}\end{array}$ & $\mathrm{CT}$ & $\begin{array}{c}\text { NMP } \\
100 \mathrm{~mL}^{-1}\end{array}$ & Mínimo & Máximo & & \\
\hline $\mathrm{BIO} \mathrm{I}$ & $5-2-0$ & 50 & $5-2-0$ & 50 & 20 & 170 & - & - \\
\hline BIO II & $0-0-0$ & $<2$ & $0-0-0$ & $<2$ & - & - & - & - \\
\hline
\end{tabular}

CT: combinação de tubos. NMP: número mais provável.

A manipueira é um subproduto do beneficiamento da mandioca para obtenção de farinha ou fécula, tendo em sua composição açúcares, amidos, proteínas, sais e o ácido cianídrico (HCN) (DUARTE et al., 2012). Como a manipueira foi introduzida apenas na formulação do BIO II (Tabela 2), provavelmente houve uma redução na disponibilidade de oxigênio dissolvido naquele meio, causando a morte de organismos aeróbicos (DUARTE et al., 2012), justificando a ausência dos micro-organismos patogênicos no BIO II e presença no BIO I. Outra hipótese é a concentração de HCN na manipueira, que ao entrar na célula do organismo consegue interromper o sistema respiratório através do bloqueio da enzima citrocromo oxidase promovendo anoxia celular (LINHARES et al., 2019). Ressalta-se ainda que, para a 
formulação de BIO II utilizou-se a manipueira fresca, sendo esta condição responsável pelos maiores níveis de $\mathrm{HCN}$.

Tabela 4. Parasitas encontrados nos biofertilizantes (BIO I e BIO II) após 96 dias de digestão aeróbica.

\begin{tabular}{cc}
\hline Biofertilizantes & Parasitas encontrados \\
\hline \multirow{2}{*}{ BIO I } & Ovos de Ascaris lumbricoides \\
& Ovo e larva de Ancilostomideo spp. \\
& Entamoeba histolystica \\
Entamoeba coli
\end{tabular}

Para este estudo, os biofertilizantes foram aplicados no solo, porém, como o BIO II não apresentou nenhum tipo de contaminação, novos estudos poderiam ser realizados utilizando este biofertilizante como fertilizante foliar. Ressaltando que são resultados de suma importância, uma vez que a alface é uma hortaliça folhosa e seu consumo é principalmente in natura.

Com base na análise de variância (Tabela 5), observa-se que para o efeito isolado do biofertilizante, houve interação significativa $(\mathrm{p}<0,01)$ apenas para a massa seca da raiz (MSR). No entanto, o fator concentração (C) influenciou isoladamente as variáveis de produção total (PT), produção comercial (PC), número de folhas (NF), massa seca das folhas (MSF), massa seca do caule (MSC) e não teve efeito sobre a massa seca da raiz (MSR). Houve interação significativa entre os biofertilizantes versus as concentrações (B x C) para PT, PC, NF, MSC e MSR, mas não houve interação significativa para a MSF (Tabela 5).

Tabela 5. Análise de variância das variáveis: produção total (PT), produção comercial (PC), número de folhas (NF), massa seca das folhas (MSF), massa seca do caule (MSC) e massa seca da raiz (MSR) em função dos tipos e concentrações de biofertilizantes.

\begin{tabular}{|c|c|c|c|c|c|c|c|}
\hline \multirow[b]{2}{*}{ Fonte de Variação } & \multicolumn{7}{|c|}{ Quadrado Médio } \\
\hline & GL & PT & $\mathrm{PC}$ & $\mathrm{NF}$ & MSF & MSC & MSR \\
\hline Biofertilizante (B) & 1 & $843,12^{\mathrm{ns}}$ & $619,83^{\mathrm{ns}}$ & $0,02^{\mathrm{ns}}$ & $0,91^{\mathrm{ns}}$ & $0,01^{\text {ns }}$ & $0,19^{* *}$ \\
\hline Concentração (C) & 5 & $815,86^{*}$ & $1112,32 * *$ & $12,80^{* *}$ & $1,80^{*}$ & $0,07^{* *}$ & $0,02^{\text {ns }}$ \\
\hline Interação: B x C & 5 & $1310,53^{* *}$ & $581,80 *$ & $10,16^{* *}$ & $0,99^{\text {ns }}$ & $0,05^{* *}$ & $0,24^{* *}$ \\
\hline \multicolumn{8}{|l|}{$\mathrm{C}$ dentro $\mathrm{B} 1$} \\
\hline Linear & 1 & $1796,81^{* *}$ & $900,93 *$ & $35,61^{* *}$ & - & $0,23 * *$ & $0,52^{* *}$ \\
\hline Quadrático & 1 & $9,30^{\text {ns }}$ & $790,67 *$ & $3,63^{\mathrm{ns}}$ & - & $1,1 \mathrm{e}^{-4 n s}$ & $0,02^{\mathrm{ns}}$ \\
\hline Desvio & 3 & $32,52^{\text {ns }}$ & $190,64 \mathrm{~ns}$ & $0,82^{\mathrm{ns}}$ & - & $0,03 * *$ & $0,03^{\text {ns }}$ \\
\hline \multicolumn{8}{|l|}{$\mathrm{C}$ dentro $\mathrm{B} 2$} \\
\hline Linear & 1 & $752,22^{\mathrm{ns}}$ & $448,10 \mathrm{~ns}$ & $2,81^{\mathrm{ns}}$ & - & $4,8 \mathrm{e}^{-5 \mathrm{~ns}}$ & $0,21^{* *}$ \\
\hline Quadrático & 1 & $4236,56^{* *}$ & $3715,43 * *$ & $56,62^{* *}$ & - & $0,13 * *$ & $0,11^{*}$ \\
\hline Desvio & 3 & $1246,43^{* *}$ & $681,21^{*}$ & $4,51^{\mathrm{ns}}$ & - & $0,05 * *$ & $0,12^{* *}$ \\
\hline Blocos & 2 & $959,43^{*}$ & 505,34 & $10,32^{*}$ & $0,10^{\mathrm{ns}}$ & $2,0 \mathrm{e}^{-4 \mathrm{~ns}}$ & $0,11^{* *}$ \\
\hline Resíduo & 22 & 212,42 & 148,83 & 2,01 & 0,50 & 0,04 & 0,01 \\
\hline $\mathrm{CV}(\%)$ & & 13,82 & 12,74 & 9,76 & 16,54 & 15,15 & 13,40 \\
\hline Média geral & & 105,40 & 95,79 & 9,00 & 16,55 & 0,44 & 0,95 \\
\hline
\end{tabular}

A aplicação do BIO I promoveu aumento linear da produção total, número de folhas, massa seca do caule e da raiz a uma taxa de $0,2925 \mathrm{~g} ; 0,0414$ und; $0,0033 \mathrm{~g}$ e $0,005 \mathrm{~g}$ a cada $1 \mathrm{~mL}$ de biofertilizante aplicado, respectivamente. Para a produção comercial, os dados se ajustaram melhor ao modelo de regressão quadrático, uma vez que a aplicação do BIO I promoveu a maior média na concentração de $40 \mathrm{~mL}$ com 107,40 g. Com uso do BIO II, os dados das variáveis analisadas ajustaram-se ao modelo de regressão quadrática, apresentando como maiores médias: $128,71 \mathrm{~g}$ (43,77 $\mathrm{mL}$ de biofertilizante); $127,74 \mathrm{~g}(60 \mathrm{~mL}$ de biofertilizante); $19 \mathrm{~g}(46,42 \mathrm{~mL}$ de biofertilizante); $0,528 \mathrm{~g}(47,77 \mathrm{~mL}$ de biofertilizante) e 1,002 $\mathrm{g}$ (30 mL de biofertilizante) para produção total (Figura 1A), produção comercial (Figura 1B), número de folhas (Figura 1C), massa seca do caule (Figura 1D) e massa seca de raiz (Figura $1 \mathrm{E})$, respectivamente.

Estudando o cultivo de alface fertirrigada com vinhaça, Darli et al. (2014) observaram incrementos na produção total, produção comercial e número de folhas. Dessa forma, ao observar a formulação dos biofertilizantes (Tabela 2), verificase que ambos receberam vinhaça em sua composição, no entanto, o BIO I recebeu $75 \mathrm{~L}$ a mais do que o BIO II. Ao analisar a interação do BIO I, observa-se que os resultados deste estudo corroboram com o observado por Darli et al. (2014) para a produção total (Figura 1A), produção comercial (Figura 1B) e número de folhas (Figura 1C).

Para o presente ensaio a vinhaça foi um ingrediente do biofertilizante e não aplicado de forma isolada, ou seja, as interações químicas dos ingredientes podem ser responsáveis pelos resultados obtidos. Observa-se ainda que o sangue apresenta maior concentração de nitrogênio, e o BIO I também recebeu a maior quantidade deste ingrediente (Tabela 2). O nitrogênio é responsável pela máxima expansão celular na planta e consequentemente, promove maior aporte de matéria fresca (TURAZI et al., 2006), no entanto, este aporte não foi observado quando se utilizou o BIO I em relação ao BIO II, enfatizando que estas interações podem justificar os resultados de massa fresca. 
Figura 1. Produção total (A), produção comercial (B), número de folhas (C), massa seca do caule (D) e massa seca da raiz (E) da alface em função da interação entre tipos e concentrações de biofertilizante. Médias seguidas de mesma letra minúscula para os biofertilizantes não diferem entre si dentro da mesma concentração.
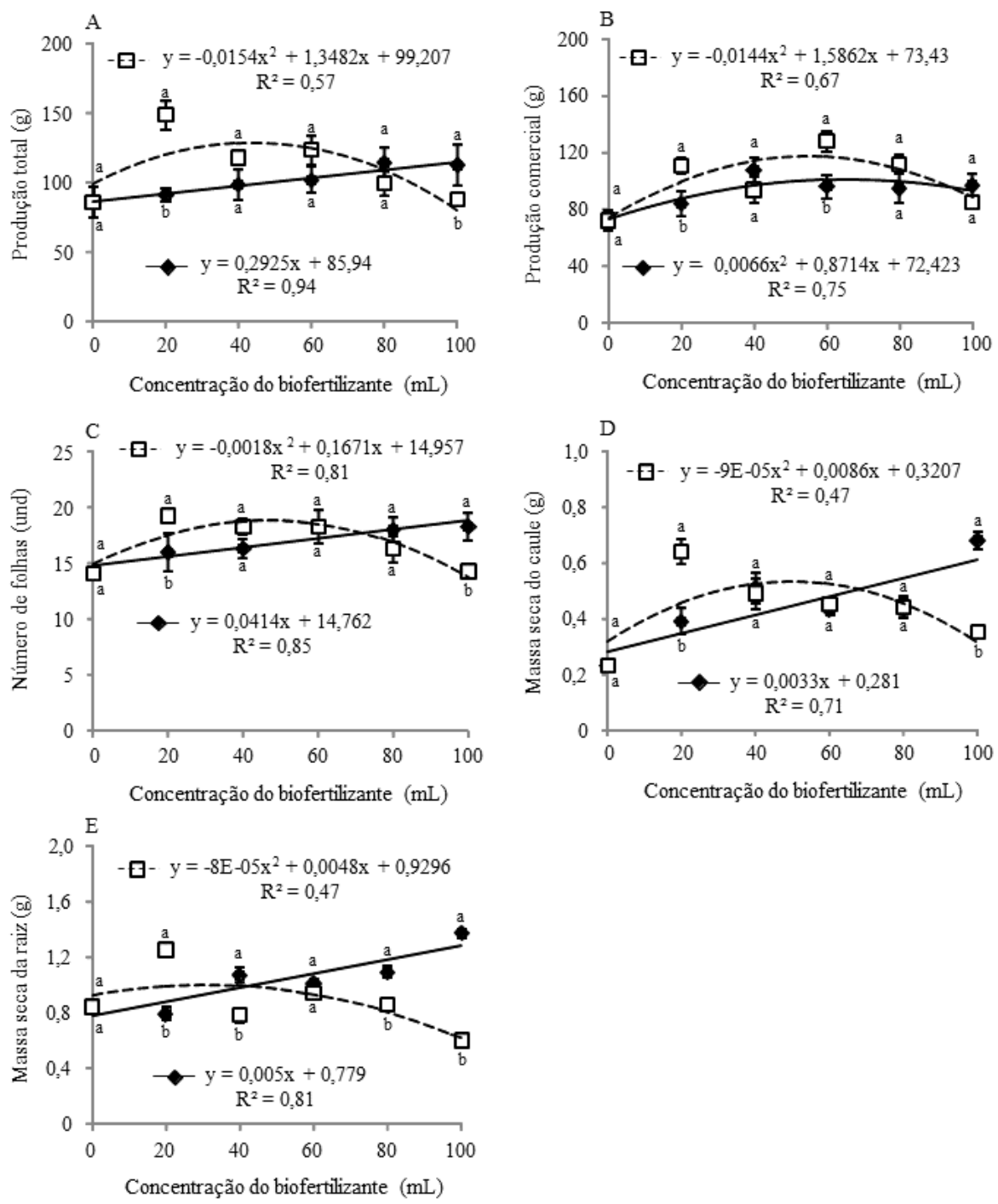

Biofertilizante I

A utilização de biofertilizante promove a fertilidade dos agroecossistemas, não somente pelo nível específico de determinado nutriente, mas por meio de sua diversidade, composição mineral e capacidade de armazená-los para o desenvolvimento das plantas (MUELLER et al., 2013; ZIECH et al., 2014). Além disso, os biofertilizantes possuem ácidos húmicos que tem sido relacionado com o desenvolvimento de aspectos agronômicos importante das culturas, como o desenvolvimento radicular (MONTEIRO FILHO et al., 2017).

Ressalta-se ainda que a relação entre a fonte nutricional (biofertilizante) e a fertilidade do solo no momento da aplicação é um dos principais fatores que influenciam os resultados obtidos para o rendimento da cultura (PINHEIRO et al., 2019). Assim, como a transformação dos nutrientes do solo pelos micro-organismos, que também podem atuar de forma antagônica ou sinérgica na disponibilidade nutricional para a cultura (SILVA et al., 2019a; 2019b).

曰- Biofertilizante II

Ziech et al. (2014) investigando diferentes fontes de adubação, constataram que não houve diferença significativa entre o composto orgânico, fertilizante mineral e o tratamento controle (sem adubação) no primeiro cultivo da alface. Os autores justificaram estes resultados a partir da fertilidade natural da área experimental que supriu as exigências nutricionais da cultura. No presente estudo também pode se observar uma boa fertilidade da área (Tabela 1) e avaliação dos biofertilizantes apenas no primeiro ciclo de cultivo da alface, o que pode justificar os resultados obtidos para a massa seca das folhas (Figura 2).

As hortaliças folhosas respondem bem a adubação orgânica e consequentemente, apresentam maior aporte em suas características agronômicas (OLIVEIRA et al., 2010). No entanto, é preciso considerar o cultivo sucessivo, que promove maior resultado em consequência da mineralização promovida 
pelos micro-organismos que habitam o solo (ZIECH et al., 2014; PINHEIRO et al., 2019).

Figura 2. Massa seca das folhas (B) da alface em função do efeito isolado das concentrações do biofertilizante.

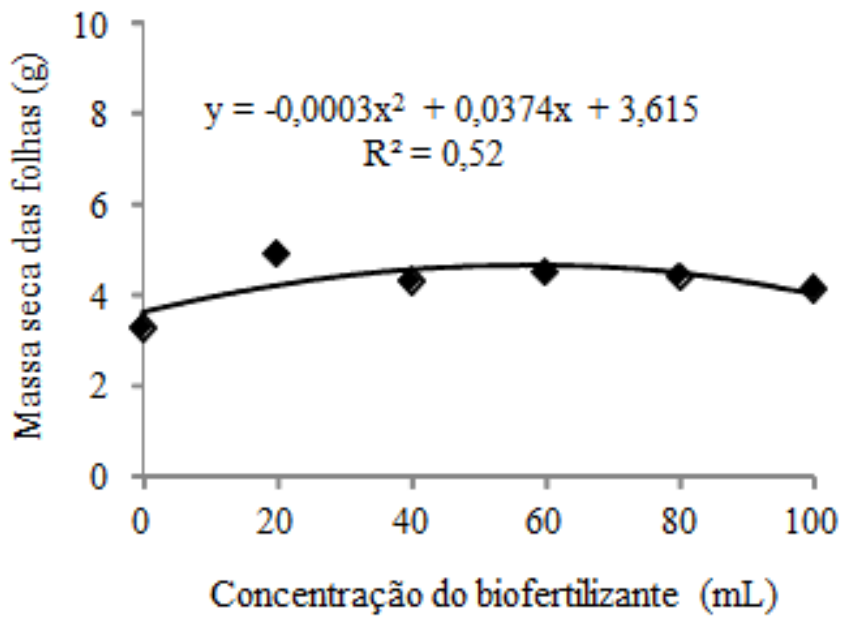

A resposta da produtividade da cultura com resíduos orgânicos está estritamente ligada à concentração da fonte nutricional e a composição dessas fontes. Podendo ocorrer desde aumento significativo na produtividade, até queda na qualidade da cultura. Segundo Biserra et al. (2020) a aplicação de $4 \mathrm{~L}$ de biofertilizante (formulado apenas com água e esterco bovino) por $15 \mathrm{dm}^{-3}$ de solo promoveu maior acúmulo de massa seca de forragem de raiz do capim-piatã (Brachiaria brizantha cv. BRS Piatã), no entanto, quando se aplicou o biofertilizante houve menores concentrações de fibra, influenciando negativamente na qualidade da planta. Silva et al. (2019b) relataram que a utilização de biofertilizante promoveu o rendimento da alface, no entanto, sua concentração e ingredientes que compõe a formulação precisam ser consideradas, pois podem afetar negativamente o desempenho da cultura.

Os resultados encontrados nesse estudo mostram que o uso de resíduos orgânicos gerados no meio rural se justifica não apenas pelo aumento no rendimento das culturas, mas também por uma possível diminuição dos custos com a adubação e maximização da reciclagem de nutrientes no próprio agroecossistema. Segundo Batista et al. (2019), o uso de biofertilizantes líquidos via aplicação no solo tem demostrado viabilidade econômica e sustentabilidade em relação ao uso de fertilizantes minerais, tornando-se assim uma importante ferramenta para sustentabilidade agrícola.

Esta autonomia é essencial para a agricultura familiar, uma vez que o cultivo da alface tem expressiva importância econômica, por ser de fácil manejo, ciclo curto, apresentar alta produtividade e rápido retorno financeiro, além de promover a segurança e soberania alimentar da família.

\section{CONCLUSÕES}

O BIO II não teve contaminação bacteriana e parasitológica, enquanto o BIO I apresentou contaminação com coliformes totais e fecais, Ascaris lumbricoides, Ancilostomideo spp., Entamoeba histolystica e Entamoeba coli.

A aplicação do BIO I promoveu aumento linear na produção total, número de folhas, massa seca do caule, massa seca da raiz; e para a produção comercial o maior rendimento foi obtido na concentração de $40 \mathrm{~mL}$. A aplicação do BIO II promoveu os maiores rendimentos nas concentrações de $40 \mathrm{~mL}$ e $60 \mathrm{~mL}$ para as variáveis analisadas.

\section{AGRADECIMENTOS}

Ao Programa Institucional de Bolsa de Iniciação Científica (PIBIC) da Universidade Estadual da Paraíba (UEPB).

\section{REFERÊNCIAS}

AOAC, Association of Official Analytical Chemistry. Offcial methods of analysis of AOAC international. v.2, 16 ed., Arlington, 1995.

BISERRA, T. T.; PAIVA, L. M.; FERNANDES, H. J.; DUARTE, C. F. D.; FLEITAS, A. C.; SILVA, A. O. Produção e valor nutritivo de Capim-Piatã submetido à adubação orgânica e química. Nativa, v. 8, n. 1, p. 1-7, 2020. 10.31413/nativa.v8i1.7450.

BATISTA, G. S.; SILVA, J. L.; ROCHA, D. N. S.; SOUZA, A. R. E.; ARAUJO, J. F.; MESQUITA, A. C. Crescimento inicial do meloeiro em função da aplicação de biofertilizantes no cultivo orgânico. Revista Brasileira De Agropecuária Sustentável, v. 9, n. 2, p. 24-32, 2019. 10.21206/rbas.v9i2.3072

DARLI, A. B.; CARVALHO NETO, O. F.; MAZZONETTO, F.; CORBANI, R. Z. Fertirrigação com vinhaça concentrada no desenvolvimento da alface. Revista Agrogeoambiental, v. 6, n. 2, p. 93-99, 2014. 10.18406/2316-1817v6n22014559.

DUARTE, A. S.; SILVA, Ê. F. F.; ROLIM, M. M.; FERREIRA, R. F. A. L.; MALHEIROS, S. M. M.; ALBUQUERQUE, F. S. Uso de diferentes doses de manipueira na cultura da alface em substituição à adubação mineral. Revista Brasileira de Engenharia Agrícola e Ambiental, v. 16, n. 3, p. 262-267, 2012. 10.1590/s1415-43662012000300005.

FAQUIN, V.; ANDRADE, A. T. Nutrição mineral e diagnose do estado nutricional de hortaliças. Lavras: UFLA/FAEPE. 88p, 2004.

FERNANDES, J. D.; MONTEIRO FILHO, A. F.; CHAVES, L. H. G.; GONÇALVES, C. P.; CRUZ, M. P. Formulação de biofertilizante utilizando a ferramenta SOLVER do Microsoft Office. Revista Verde de Agroecologia e Desenvolvimento Sustentável, v.6, n.4, p. 101-105, 2011.

FERREIRA, D. F. Sisvar: a computer statistical analysis system. Ciência e Agrotecnologia, v. 35, n. 6, p. 1039-1042, 2011. 
LAPÔRTO, M.; ALVES, J. C.; SOUZA, A. P.; ARAÚJO, R. C.; ARRUDA, J. A. A.; TOMPSON JÚNIOR, U. Doses de nitrogênio no acúmulo de nitrato e na produção da alface em hidroponia. Horticultura Brasileira, v. 30, n. 3, p. 539-543, 2012. 10.1590/s0102-05362012000300030.

LINHARES, A. L. F. A.; SEIXAS, B. C.; MAIA, J. O. M. Determinação do ácido cianídrico em mandioca. e-Scientia, v. 11, n. 2, p. 1-7, 2019.

MONTEIRO FILHO, A. F.; AZEVEDO, M. R. Q. A.; AZEVEDO, C. A. V.; FERNANDES, J. D.; SILVA, C. R.; SILVA, Y. S. Growth of hydroponic lettuce with optimized mineral and organomineral nutrient solutions. Revista Brasileira de Engenharia Agrícola e Ambiental, v. 21, n. 3, p. 191-196, 2017. 10.1590/1807-1929/agriambi.v21n3p191-196.

MUELLER, S.; WAMSER, A. F.; SUZUKI, A.; BECKER, W. F. Produtividade de tomate sob adubação orgânica e complementação com adubos minerais. Horticultura Brasileira, v. 31, n. 1, p. $86-92,2013.10 .1590 / \mathrm{s} 0102-05362013000100014$

OLIVEIRA, E. Q.; SOUZA, R. J.; CRUZ, M. C. M.; MARQUES, V. B.; FRANÇA, A. C. Produtividade de alface e rúcula, em sistema consorciado, sob adubação orgânica e mineral. Horticultura Brasileira, v. 28, p. 36-40, 2010.

PERAZZOLI, B. E.; PAULETTI, V.; QUARTIERI, M.; TOSELLI, M.; GOTZ, L. F. Changes in leaf nutrient content and quality of pear fruits by biofertilizer application in northeastern Italy. Revista Brasileira de Fruticultura, v. 42, n. 1, p. 1-12, 2020. 10.1590/0100-29452020530.

PINHEIRO, R. C.; PEREIRA, J. L.; REZENDE, C. F. A. Adubação biológica associada a adubação química nos parâmetros de solo, nutricional e produtivo do milho. Revista Brasileira de Agropecuária Sustentável, v. 9, n. 04, p. 9-17, 2019. 10.21206/rbas.v9i04.8459.

SANTOS, S.-C. S.; FERNANDES, P. D.; QUEIROZ, M. F.; ARRIEL, N. H. C.; RIBEIRO, V. H. A.; FERNANDES, J. D. Physiology and production of sesame genotypes BRS-Seda and Preto under organomineral fertilization. Revista Brasileira de Engenharia Agrícola e Ambiental, v. 23, n. 12, p. 914-918, 2019. 10.1590/1807-1929/agriambi.v23n12p914-918.

SILVA, M. B.; ARAÚJO, J. F.; GALVÃO, E. R.; BATISTA, F. P. R. Produção e qualidade de acerola com biofertilizantes líquidos sob o cultivo biodinâmico. Revista Ouricuri, v. 2, n. 2, p. 125-137, 2012.

SILVA, F. L.; LIMA, A. S.; SANTOS, J. M.; ALVES, J. M.; SOUSA, C. S.; SANTOS, J. G. R. Biofertilizantes na produção da videira Isabel. Revista Verde de Agroecologia e Desenvolvimento Sustentável, v. 14, n. 2, p. 211-217, 2019a. $\underline{10.18378 / \text { rvads.v14i2.6200. }}$.

SILVA, C. F. A.; LATTINI, A. O.; LOFRANO, R. C. Z. Efeito e biofertilizante no crescimento de alface, rúcula, tomate, cebolinha e repolho. Revista Gestão e Sustentabilidade Ambiental, v. 8, n. 3, p. 278-287, $2019 \mathrm{~b}$. 10.19177/rgsa.v8e32019278-287.

SOUSA, M. F.; SILVA, L. V.; BRITO, M. D.; FURTADO, D. C. M. Tipos de controle alternativo de pragas e doenças nos cultivos orgânicos no estado de Alagoas, Brasil. Revista Brasileira de Agroecologia, v. 7, n. 1, p. 132-138, 2012.

TAKAYANAGUI, O. M.; OLIVEIRA, C. D.; BERGAMINI, A. M. M.; CAPUANO, D. M.; OKINO, M. H. T.; FEBRÔNIO, L. H. P.; CASTRO SILVA, A. A. M. C.; OLIVEIRA, M. A.; RIBEIRO, E. G. A.; TAKAYANAGUI, A. M. M. Fiscalização de verduras comercializadas no município de Ribeirão Preto, SP. Revista da Sociedade Brasileira de Medicina Tropical, v. 34, n. 1, p. 37-41, 2001.

TURAZI, C. M. V.; JUNQUEIRA, A. M. R.; OLIVEIRA, S. A.; BORGO, L. A. Acúmulo de nitrato em alface em função da adubação, horário de colheita e tempo de armazenamento. Horticultura Brasileira, v. 24, n. 1, p. 65-70, 2006. 10.1590/s0102-05362006000100013.

ZIECH, A. R. D.; CONCEIÇÃO, P. C.; LUCHESE, A. V.; PAULUS, D.; ZIECH, M. F. Cultivo de alface em diferentes manejos de cobertura do solo e fontes de adubação. Revista Brasileira de Engenharia Agrícola e Ambiental, v. 18, n. 9, p. 948-954, 2014. 10.1590/1807-1929/agriambi.v18n09p948-954. 